\title{
Monoamine Oxidase Inhibition Causes a Long-Term Prolongation of the Dopamine-Induced Responses in Rat Midbrain Dopaminergic Cells
}

\author{
Nicola B. Mercuri, Mariangela Scarponi, Antonello Bonci, Antonio Siniscalchi, and Giorgio Bernardi \\ Clinica Neurologica, Dipartimento Sanitá Pubblica, Universitá di Roma Tor Vergata and Istituto Ricerca e Cura a Carattere \\ Scientifico Ospedale Santa Lucia, Roma, Italy
}

\begin{abstract}
The way monoamine oxidase (MAO) modulates the depression of the firing rate and the hyperpolarization of the membrane caused by dopamine (DA) on rat midbrain dopaminergic cells was investigated by means of intracellular recordings in vitro. The cellular responses to DA, attributable to the activation of somatodendritic D2/3 autoreceptors, were prolonged and did not completely wash out after pharmacological blockade of both types (A and B) of MAO. On the contrary, depression of the firing rate and membrane hyperpolarization induced by quinpirole (a direct D2 receptor agonist) were not affected by MAO inhibition. Furthermore, although the inhibition of DA reuptake by cocaine and nomifensine caused a short-term prolongation of DA responses, the combined inhibition of MAO A and B enzymes caused a long-term prolongation of DA effects. More-
\end{abstract}

over, the effects of DA were not largely prolonged during the simultaneous inhibition of MAO and the DA reuptake system. Interestingly, the actions of amphetamine were not clearly augmented by MAO inhibition.

From the present data it is concluded that the termination of DA action in the brain is controlled mainly by MAO enzymes. This long-term prolongation of the dopaminergic responses suggests a substitutive therapeutic approach that uses MAO inhibitors and DA precursors in DA-deficient disorders in which continuous stimulation of the dopaminergic receptors is preferable.

Key words: pargyline; cocaine; nomifensine; intracellular recordings; substantia nigra; ventral tegmental area
The time course of the action of dopamine (DA) on its receptors has been believed to be controlled primarily by the DA reuptake system. This assumption has been substantiated by extensive studies demonstrating that the concentration of DA (Church et al., 1987; Di Chiara and Imperato, 1988; Galloway, 1988; Nomikos et al., 1990; Kalivas and Duffy, 1991) and the physiological effects of this catecholamine in the brain are enhanced by agents that are able to block its transporter (Einhorn et al., 1988; Williams and Lacey, 1989; Lacey et al., 1990; Mercuri et al., 1991a,b,c). It has been suggested, however, that the tone of DA is regulated not only by the DA reuptake system but also by the DA synthesizing and degrading enzymes. Accordingly, we have shown recently that stimulation of DA synthesis by levodopa (Mercuri et al., 1990) and blockade of DA degradation by MAO inhibitors (MAOI) (Mercuri et al., 1996) cause a DA-mediated depression of the firing discharge of the dopaminergic neurons in the ventral mesencephalon.

To study possible changes in the DA-induced responses caused by the inhibition of MAO enzymes, we made intracellular electrophysiological recordings from dopaminergic neurons in the rat mesencephalon maintained in vitro. Using the same preparation, we also examined the effects of two DA reuptake inhibitors, cocaine and nomifensine, on responses to exogenously applied DA. Contrary to the common belief that the effects of DA are regulated mainly by the transporter, we found that a more effec-

\footnotetext{
Received Dec. 6, 1996; revised Jan. 6, 1997; accepted Jan. 13, 1997.

We thank G. Gattoni, M. Federici, and M. Tolu for their excellent technical assistance.

Correspondence should be addressed to Dr. Nicola B. Mercuri, IRCCS, Santa Lucia, Via Ardeatina, n. 306, 00179, Roma, Italy.

Copyright (C) 1997 Society for Neuroscience 0270-6474/97/172267-06\$05.00/0
}

tive mechanism of termination of DA action in the brain occurs via its deamination by MAO.

\section{MATERIALS AND METHODS}

Preparation of the tissue. The method used has been described previously (Mercuri et al., 1995). In brief, Wistar rats (150-250 gm) were anesthetized with ether and killed. The brain was removed, and horizontal slices (thickness $300 \mu \mathrm{m}$ ) were cut by a vibratome starting from the ventral surface of the midbrain. In some experiments in which amphetamine was used, coronal slices of the ventral mesencephalon were also cut (Lacey et al., 1987). A single slice containing the substantia nigra and the ventral tegmental area (VTA) was then transferred into a recording chamber and submerged completely in an artificial cerebrospinal fluid with a continuously flowing $(2.5 \mathrm{ml} / \mathrm{min})$ solution at $35^{\circ} \mathrm{C}, \mathrm{pH} 7.4$. This solution contained (in mM): $126 \mathrm{NaCl}, 2.5 \mathrm{KCl}, 1.2 \mathrm{MgCl}_{2}, 1.2 \mathrm{NaH}_{2} \mathrm{PO}_{4}, 2.4 \mathrm{CaCl}_{2}$, 11 glucose, $20 \mathrm{NaHCO}_{3}$, gassed with $95 \% \mathrm{O}_{2} / 5 \% \mathrm{CO}_{2}$.

Recordings. The recording electrodes (Clark 1.0-1.5 mm, thick wall), pulled by Narishige vertical and horizontal pullers, were filled with $2 \mathrm{M}$ $\mathrm{KCl}$ and had a tip resistance of $40-80 \mathrm{M} \Omega$. The signals were obtained by an amplifier (Axoclamp-2A, Axon Instruments, Foster City, CA) and displayed on a pen recorder (Gould $2400 \mathrm{~S}$ ) and on a digital oscilloscope (Tektronix) or saved on a tape recorder (Biologic) for off-line analysis. The tips of the electrodes were placed in the substantia nigra pars compacta $(\mathrm{SNc})$ and VTA by using a dissecting microscope.

Application of drugs. Drugs were made in stock solutions and bathapplied at known concentrations via a three-way tap system. A complete exchange of the solution in the recording chamber occurred in $\sim 1$ min.

The following substances were used: DA hydrochloride; cocaine hydrochloride; (+)-amphetamine sulfate; haloperidol; pargyline, which blocks both types of MOA (A and B) (Butcher et al., 1990), (Sigma, St. Louis, MO); quinpirole (LY 171555, Lilly); nomifensine (HoechstRoussel Pharmaceuticals, Frankfurt, Germany); clorgyline, which is more selective for type A MAO (Johnston, 1968); and deprenyl, which is more selective for type B MAO (Knoll and Magyar, 1972) (Research Biomedicals, Natick, MA); and L-sulpiride (Ravizza). The changes in firing rate induced by the drugs were normalized as a percentage of control (each neuron served as its own control). In some experiments the slices were 


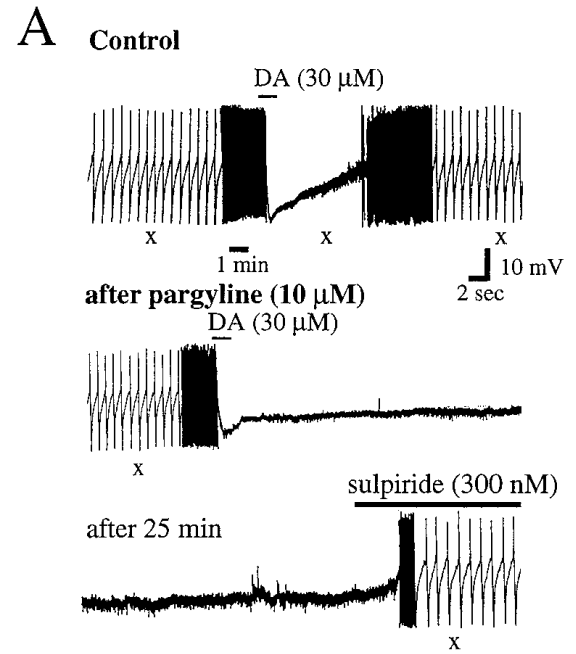

B
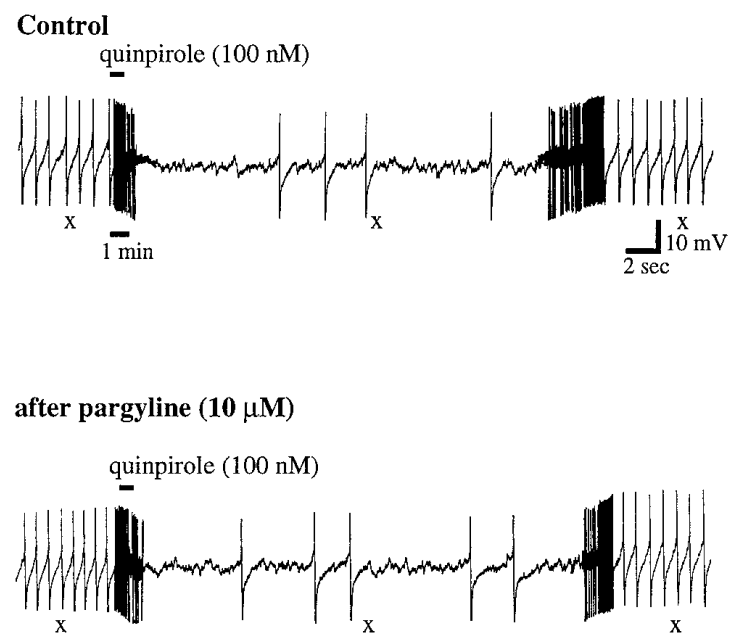

Figure 1. Pargyline prolongation of DA responses. $A$, The bath application of DA (30 $\mu \mathrm{M})$ produced a reversible hyperpolarization and inhibition of firing. The bar indicates the period of DA application. A long-term prolongation of the DA-induced hyperpolarization and inhibition (DA was applied for the same period of control) was observed when pargyline $10 \mu \mathrm{M}$ was superfused on the cells for 30 min. The subsequent application of sulpiride (300 $\mathrm{nM}$ ) antagonized the prolonged response to DA application. $B$, The inhibitory effects of quinpirole (100 nM) were not affected by the superfusion of pargyline $(10 \mu \mathrm{M})$ for $30 \mathrm{~min}$. Note that in this and the following figures the speed of the chart was changed at the points indicated (see $x$ underneath) to show individual action potentials. Full amplitude of the action potential was not reproduced because of the limited frequency of the pen recorder.

preincubated for $2-3 \mathrm{hr}$ with pargyline $(1-10 \mu \mathrm{M})$, clorgyline $(1-30 \mu \mathrm{M})$, or deprenyl $(1-10 \mu \mathrm{M})$ to allow sufficient time for steady-state MAO inhibition to develop (Harsing and Vizi, 1984), and then the neuronal responses to DA were evaluated.

Data were expressed as mean \pm SEM.

\section{RESULTS}

\section{Electrophysiological and pharmacological properties of DA cells}

The present results are based on intracellular recordings made from 120 spontaneous-firing midbrain dopaminergic cells in vitro. The properties of these "principal" neurons have been described (Llinas et al., 1984; Kita et al., 1986; Grace and Onn, 1989; Lacey et al., 1989; Johnson and North, 1992; Mercuri et al., 1995). They fired at a mean rate of $1.5 \mathrm{~Hz}$, had a relatively long-lasting spike (>1.2 $\mathrm{msec}$ ), and showed a voltage-dependent sag in membrane potential with hyperpolarizing pulses. A brief superfusion of DA (10-30 $\mu \mathrm{M}$ for 1-2 min) caused reversible membrane hyperpolarization and inhibition of spontaneous firing. When application of the solution containing DA was discontinued, the firing rate returned to basal value within 5-10 min (Figs. 1 $A, 2$ ). A reversible inhibition of the spontaneous firing and a hyperpolarization were also observed when quinpirole (30 nM-1 MM for 30-60 sec) $(n=7)$ or $(+)$ amphetamine $(10-20 \mu \mathrm{M})$ were bath-applied to these neurons $(n=6)$ (Figs. $1 B, 6)$. The cellular responses to DA and quinpirole application are attributable mainly to the activation of somatodendritic D2/D3 type receptors, which increases potassium conductance (Lacey et al., 1987). Furthermore, the membrane hyperpolarization and the depression of the spontaneous discharge caused by amphetamine are attributable to the release of endogenous DA from calcium-insensitive stores (Mercuri et al., 1989).

\section{The inhibition of MAO potentiates the effects of exogenously applied DA but not the effects of quinpirole}

After testing the effects of DA and quinpirole on the principal cells, these cells were then superfused with the nonspecific MAO A and B inhibitor pargyline (1-100 $\mu \mathrm{M}$ for 20-50 min). At a concentration of $100 \mu \mathrm{M}$, pargyline often reduced the spontaneous

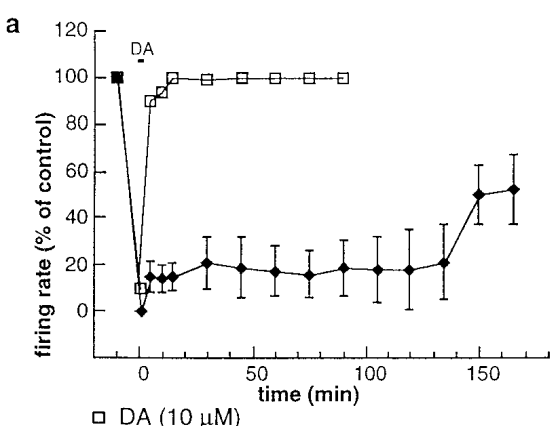

- DA $(10 \mu \mathrm{M})+$ pargyline $(10 \mu \mathrm{M})$

b

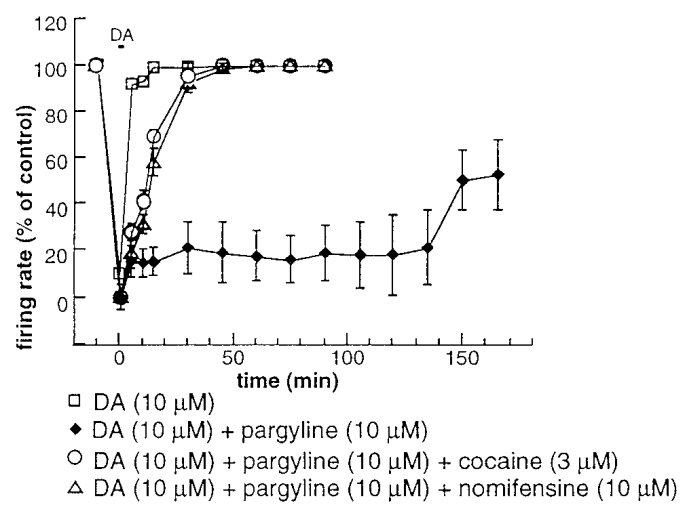

Figure 2. Long-term prolongation of the DA-responses in pargyline and effects of the combined perfusion of DA uptake blockers. $a$, Plot of the firing rate (percentage of control) versus time in control condition and after a treatment with pargyline $(10 \mu \mathrm{M})$. Note that pargyline produced an enduring DA-induced firing inhibition. The bar illustrates the DA washout starting point. Note that the firing remained depressed even after $160 \mathrm{~min}$ of DA washout. In $b$, the previous graph was superimposed with two other graphs to observe the different changes in DA responses caused by pargyline alone or in combination with cocaine $(3 \mu \mathrm{M})$ and nomifensine $(10 \mu \mathrm{M})$. Data were obtained from 4-10 determinations. Error bars represent SEM. 
A

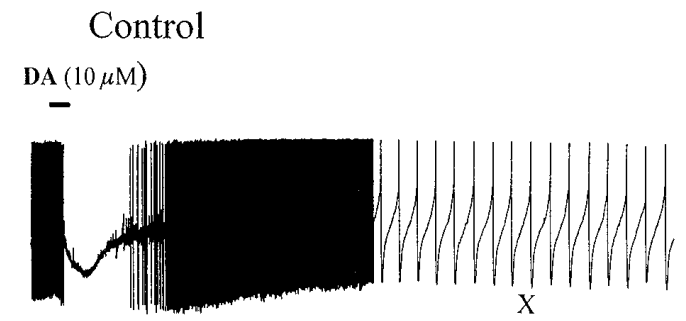

B

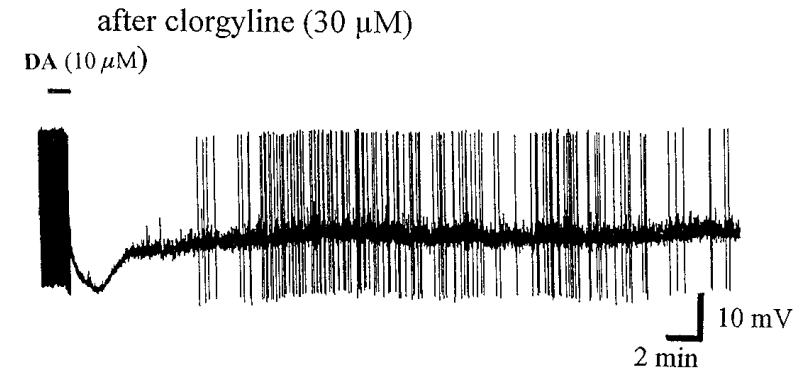

sulpiride $(300 \mathrm{nM})$

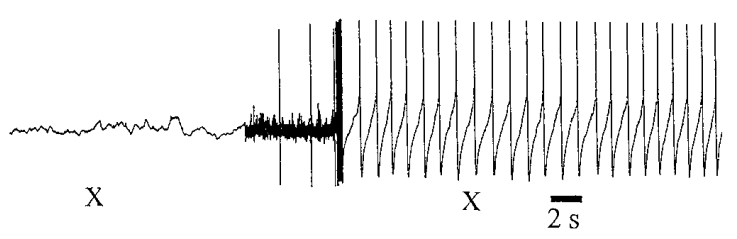

Figure 3. Effects of clorgyline on the DA-induced responses. $A$, Control response to DA application. $B$, Long-term prolongation of DA-induced inhibition after clorgyline treatment. Note that sulpiride was able to restore the control firing discharge of the cells, indicating a protracted activation of the somatodendritic D2-like autoreceptors.

discharge of the neurons (Mercuri et al., 1996). We tried to counteract this inhibitory effect, however, by injecting steady-state depolarizing current into the cells before testing DA again. In all neurons $(n=40)$ treated with pargyline (3-100 $\mu \mathrm{M})$ the inhibition and hyperpolarization caused by DA were prolonged, and in most cases these effects did not recover completely even after $1 \mathrm{hr}$ or more of washout (Figs. 1A,2). Conversely, the cellular effects caused by the direct D2 agonist quinpirole were not affected by MAO inhibition (Fig. $1 B)(n=5)$.

Although we observed a slight prolongation of the DA-induced responses with $1 \mu \mathrm{M}$ pargyline (three of five cells), the threshold for significant action of this drug was $3 \mu \mathrm{m}$. Once a sustained DA inhibition was induced in pargyline-treated neurons, it could be readily reversed by superfusion of the $\mathrm{D} 2 / \mathrm{D} 3$ receptor antagonist sulpiride $(100 \mathrm{nM}-1 \mu \mathrm{M})($ Fig. $1 A)(n=10)$ and haloperidol $(10$ $\mu \mathrm{M})(n=4)$ (not shown). In some cells treated with pargyline, however, not even the application of sulpiride $(n=8)$ or haloperidol $(n=2)$ fully antagonized the long-lasting depressant effects caused by DA.

An enduring change in the DA-induced inhibition was also obtained in cells pretreated with pargyline $(3-10 \mu \mathrm{M})(n=15)$ (not illustrated).

A long-lasting prolongation of the DA-induced inhibition was obtained by superfusion of either the preferential MAO A or B inhibitors clorgyline and deprenyl, respectively, at concentrations ranging from 10 to $30 \mu \mathrm{M}$ for 30-40 min (four cells for each compound) (Figs. 3, 4). At lower concentrations (300 nM-3 $\mu \mathrm{M}$ ) these substances were ineffective. A similar, long-lasting increase
A

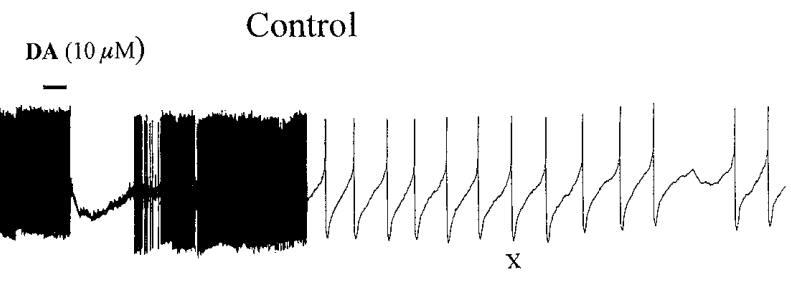

B
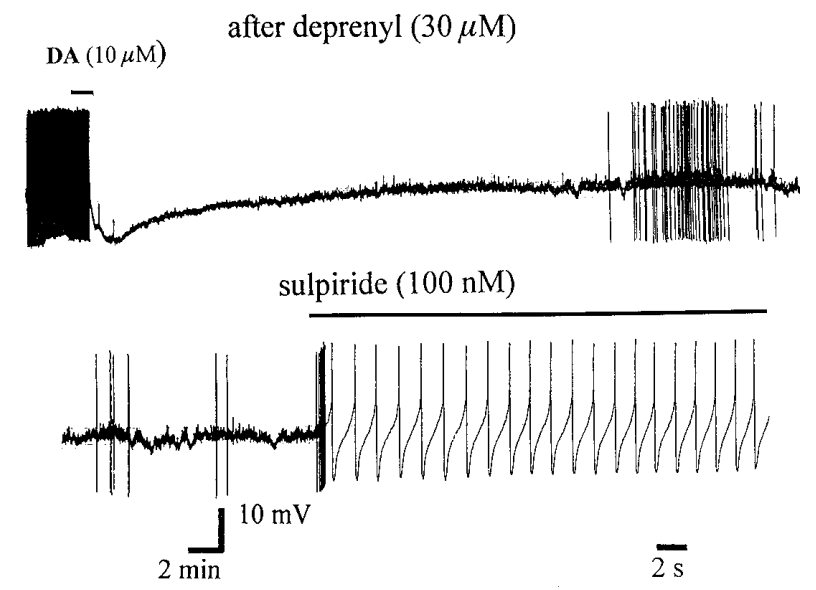

Figure 4. Effects of deprenyl on DA-induced responses. $A$, The superfusion of DA induced a reversible inhibition of this principal cell. $B$, After the bath application of deprenyl the depressant effect of DA was potentiated. This long-lasting inhibition was antagonized by sulpiride $(100 \mathrm{nM})$.

in DA-induced responses was also observed in neurons pretreated with either clorgyline $(30 \mu \mathrm{M})$ or deprenyl $(10 \mu \mathrm{M})$ (three cells for each compound), whereas lower concentrations $(1-3 \mu \mathrm{M})$ were not effective (not illustrated).

\section{Comparison of DA effects during MAOI with DA actions during reuptake inhibition}

In the presence of cocaine $(3 \mu \mathrm{M})$ and nomifensine $(10 \mu \mathrm{M})$, the amplitude and duration of cellular responses (inhibition of firing and membrane hyperpolarization) to DA (10 $\mu \mathrm{M}, 1 \mathrm{~min})$ application were increased (Fig. 5). Both cocaine and nomifensine decreased the firing activity of the dopaminergic cells (from 15 to $40 \%$ of control) by hyperpolarizing the membrane $(1-4 \mathrm{mV})$ (Lacey et al., 1990; Mercuri et al., 1991a,b,c); however, to reestablish the control firing rate, depolarizing current (10-40 pA) was injected into the cells before DA was applied again.

Figure 5, $A b$ and $B b$, shows two graphs in which we plotted the firing rate percentage at different intervals after DA application in control conditions and in cells treated with cocaine ( $3 \mu \mathrm{M}$ for $4-9$ $\min )$ or nomifensine (10 $\mu \mathrm{M}$ for $4-9 \mathrm{~min})$. It is clear that although a long-term prolongation of the inhibitory effect of DA was caused by pargyline, only a short-term prolongation of the DAinduced firing depression was caused by cocaine or nomifensine.

\section{The simultaneous inhibition of MAO and the DA reuptake system prevents the MAOI-induced enhancement of DA responses}

When pargyline (10 $\mu \mathrm{M}$ for $20-40 \mathrm{~min})$ and nomifensine $(3 \mu \mathrm{M})$ $(n=5)$ or cocaine $(3 \mu \mathrm{M})(n=6)$ were perfused simultaneously on the dopaminergic cells, no long-term prolongation of DA responses was observed, but only a reversible potentiation of DA effects was seen (Figs. 2, 5). 
Control

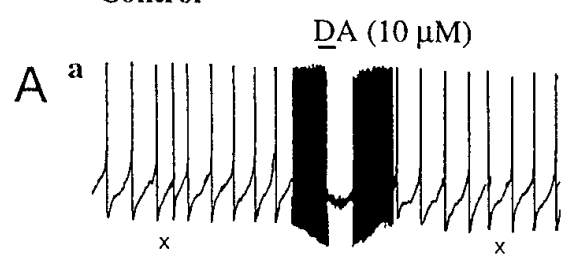

after cocaine $(3 \mu \mathrm{M})$

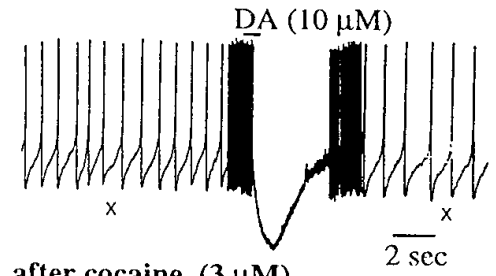

after cocaine $(3 \mu \mathrm{M})$

plus pargyline $(10 \mu \mathrm{M})$

DA $(10 \mu \mathrm{M})$

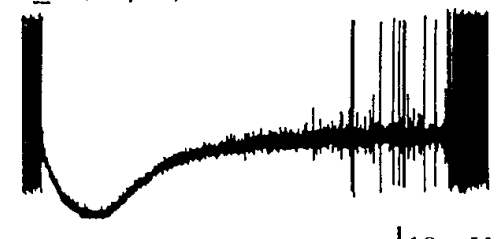

$\underset{2 \min }{10}$

b

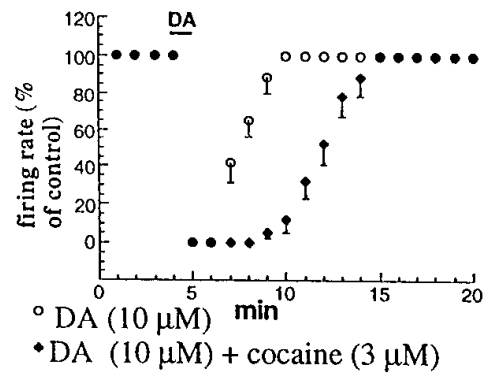

c

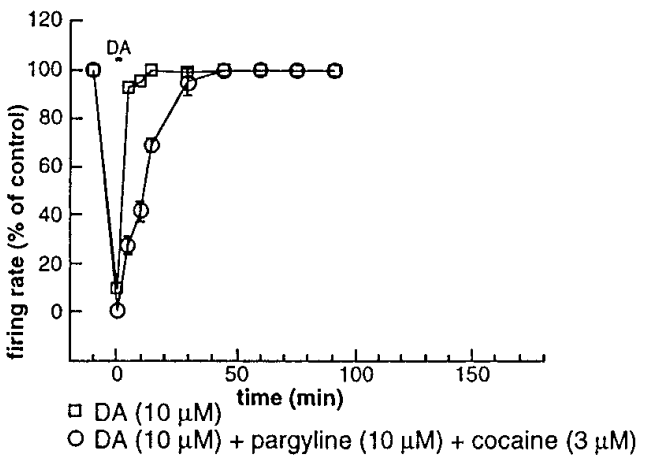

Control

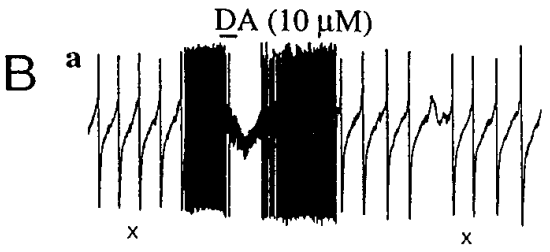

after nomifensine $(10 \mu \mathrm{M})$

DA $(10 \mu \mathrm{M})$

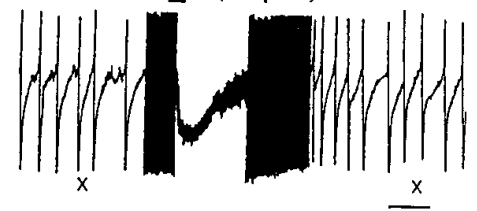

after nomifensine $(10 \mu \mathrm{M}) \overline{2 \mathrm{sec}}$ plus pargyline $(10 \mu \mathrm{M})$

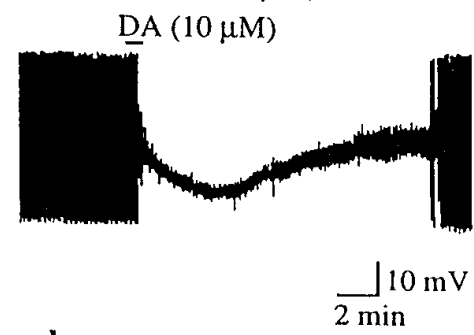

b

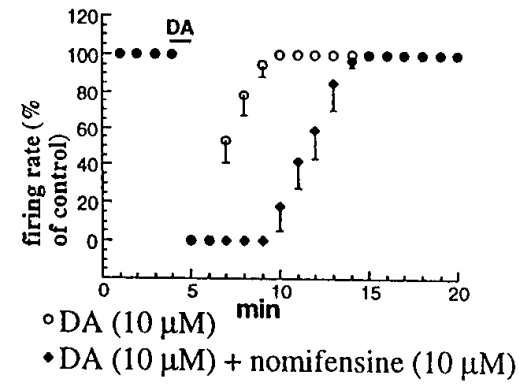

c

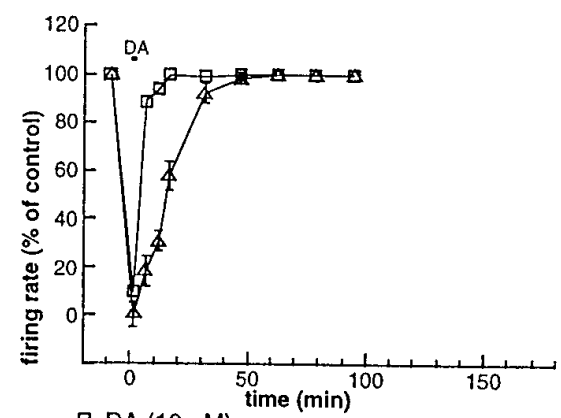

व $\mathrm{DA}(10 \mu \mathrm{M})$

$\triangle \mathrm{DA}(10 \mu \mathrm{M})+$ pargyline $(10 \mu \mathrm{M})+$ nomifensine $(10 \mu \mathrm{M})$

Figure 5. Effects of DA uptake inhibitors on DA-induced responses. $A a$, Potentiation of the DA responses by cocaine ( $3 \mu \mathrm{M})$ and prevention of the pargyline-induced long-term prolongation of DA inhibition. $A b$, The graph shows the cocaine-induced short-term prolongation of the inhibitory period caused by DA (each point represents four to six determinations). $A c$, Prevention of the long-term prolongation of the DA-induced inhibition in the presence of cocaine $(3 \mu \mathrm{M})$. Ba, Potentiation of DA responses by nomifensine. In the presence of pargyline plus nomifensine the long-term prolongation of the DA-induced inhibitory effect caused by pargyline was not observed. $B b$, The graph shows the nomifensine-induced short-term prolongation of the DA-induced inhibitory period (each point represents four to five determinations). $B c$, Prevention of the long-term prolongation of the DA-induced inhibition in the presence of nomifensine $(10 \mu \mathrm{M})$. Note that the graphs in $A c$ and $B c$ are shown superimposed in Figure $2 b$. 

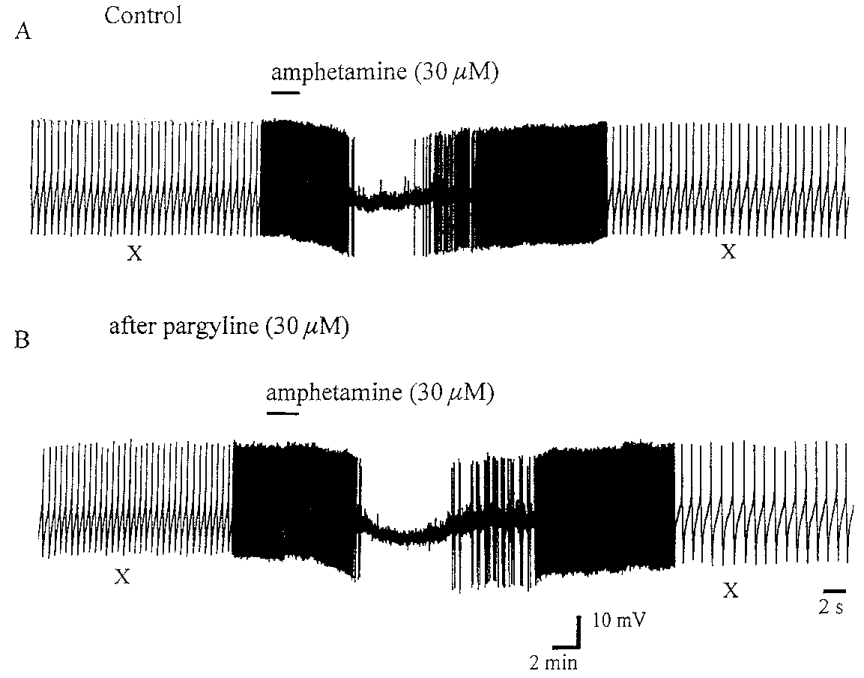

Figure 6. Effects of pargyline on amphetamine-induced responses. $A$, Control response to amphetamine. $B$, After pargyline application (30 $\min$ ), the membrane hyperpolarization and the inhibition of firing caused by amphetamine were slightly potentiated.

\section{The inhibition of MAO induces a short-term prolongation of the effects of endogenous DA}

To test whether the blockade of MAO would enhance the effects of exogenously applied DA as well as the electrophysiological effects caused by endogenous (amphetamine-released) DA, we designed experiments in which amphetamine was tested before and after the bath application of pargyline $(10-30 \mu \mathrm{M})$. Under these conditions, the reversible membrane hyperpolarization and inhibition of firing caused by the superfusion of $(+)$ amphetamine $(10-20 \mu \mathrm{M})$ were slightly potentiated $(13.1 \pm 2.8 \%$ of control; $n=$ 9) (Fig. 6) after pargyline treatment $(30 \mathrm{~min})$. To rule out the possibility that the lack of effect of pargyline on amphetamine responses was caused by impaired diffusion of the drug in the damaged/cut border of the horizontal slices, three experiments were conducted to check the effects of amphetamine under MAO inhibition on dopaminergic cells of the SNc that were impaled in coronal slices. Even under these conditions, however, pargyline did not clearly enhance the effects of amphetamine.

\section{DISCUSSION}

The main finding of the present study is that the termination of DA action in the CNS is controlled more effectively by MAO enzymes than by the DA reuptake system. In fact, the ability of MAO inhibitors to induce an enduring prolongation of the electrophysiological effects of exogenously applied DA is most likely attributable to the blockade of MAO activity. Thus, although the rapid reuptake processes might contribute toward regulating the cleavage of DA from their receptors for a relatively short period of time, the degrading processes might play a major role in maintaining a dopaminergic signal in the brain for a longer period of time. This long-lasting increase in DA transmission is very likely a consequence of the drug-induced blockade of DA deamination by MAO at the mitochondrial membranes (Yang and Neff, 1974; Green et al., 1977; Weiner and Molinoff, 1989; Juorio et al., 1994), so that there is a buildup of the intracellular and consequently the extracellular concentration of this catecholamine. Under MAO inhibition, the DA reuptake system is probably fully operating. Thus, it might fail to limit the physiological effects of newly applied DA. The impaired cleavage of extracellular DA leads to continued stimulation of the DA autoreceptors, which in some cells become resistant to washout or antagonism (Lacey et al., 1987; Bowery et al., 1994). This phenomenon could explain why the D2 antagonists sulpiride and haloperidol were not able to completely reverse the DA-induced depression of firing in some experiments. A further confirmation that the long-term prolongation of DA responses is attributable to its impaired degradation is provided by the fact that the electrophysiological effects of quinpirole (a direct D2 receptor agonist that is not a substrate for MAO enzymes) were not changed during MAO inhibition. Moreover, the observation that the cellular responses to quinpirole were not prolonged after MAO inhibition seems to rule out the possibility that the long-term prolongation of DA actions is attributable to MAOI-induced changes in receptor sensitivity.

Although the presence of MAO in the dopaminergic cells is still controversial, the existence of MAO A and B enzymes in the ventral mesencephalon has already been shown in the rat and human brain (Roffler-Tarlov et al., 1971; Marsden et al., 1972; Levitt et al., 1982; Commissioning, 1985; Saura et al., 1992, 1996), and their inhibition regulates DA metabolism (Houslay et al., 1976; Green et al., 1977; Schoepp and Azzaro, 1982; Harsing and Vizi, 1984; Kito et al., 1986; Butcher et al., 1990; Juorio et al., 1994).

\section{The blockade of both forms of MAO is a necessary requisite for DA prolongation}

It is interesting to note that only a pharmacological treatment that inhibits both isoforms of MAOs was able to cause a prolongation of DA effects on the dopaminergic neurons of the rat midbrain. In fact, the prolongation of DA responses was obtained with micromolar concentrations of pargyline, clorgyline, and deprenyl. These levels of the three drugs were thought to be nonselective, because they could irreversibly affect either MAO A or B enzymes (Harsing and Vizi, 1984). This is in agreement with biochemical findings showing that DA is a substrate for both forms of MAOs (Houslay et al., 1976; Green et al., 1977; Flower et al., 1982; Schoepp and Azzaro, 1982, 1983; Harsing and Vizi, 1984; Butcher et al., 1990; Juorio et al., 1994) and with our recent electrophysiological data showing that a depression of the spontaneous firing discharge of the dopaminergic cells is caused by the simultaneous inhibition of MAO A and B enzymes (Mercuri et al., 1996).

\section{Interpretation of the effects of amphetamine and DA reuptake inhibitors}

An increased content of intracellular and then extracellular DA after MAO inhibition might be the necessary requisite for the long-lasting inhibitory effect of exogenously applied DA. When the intracellular DA stores are saturated, they cannot buffer any further increase in DA concentration caused by the bath application of this catecholamine. Thus, as a consequence of intracellular DA saturation, the extracellular levels of DA remain elevated. During amphetamineinduced DA release, however, the DA stores are depleted again in spite of MAO inhibition. Under these conditions, the neuronal responses to amphetamine may recover partially, because extracellular DA is effectively removed by the reuptake system and subsequently redistributed in the neurons to restore the depleted pools. This phenomenon may explain why the amphetamine-induced responses were not prolonged greatly by MAOI. Because we did not observe a clear-cut prolongation of the responses caused by the amphetamine-induced release of DA from dendritic trees located in the horizontal and coronal planes of the mesencephalon, it is unlikely that the scanty potentiation of amphetamine actions by MAOI are dependent on a distinct distribution of MAO enzymes in the different planes of the mesencephalic slices. 
The finding that cocaine and nomifensine prevented the pargylineinduced long-term prolongation of DA effects suggests that DA has to enter the cells throughout the uptake system to be degraded by the mitochondrial MAO. Therefore, the block of the DA-uptake system impedes the pargyline-induced loading of the neurons with DA, which is essential for the prolongation of the DA-induced effects.

\section{Clinical implications}

The observation that the responses caused by DA were consistently potentiated by MAOIs implies that an effective strategy for obtaining a continuous stimulation of DA receptors in the brain is to reduce the activity of both MAO enzymes. Thus, clinical trials should be designed to fully evaluate the potential effectiveness of a combined treatment consisting of both DA precursors (e.g., tyrosine, levodopa) and MAOIs in those neurological (Parkinson's disease) and psychiatric (depression) disorders in which a dysfunction of brain dopaminergic receptors is suspected.

\section{REFERENCES}

Bowery B, Rothwell LA, Seabrook GR (1994) Comparison between the pharmacology of dopamine receptors mediating the inhibition of cell firing in rat brain slices through the substantia nigra pars compacta and ventral tegmental area. Br J Pharmacol 112:873-880.

Butcher PS, Fairbrother IS, Kelly JS, Arbuthnott GW (1990) Effects of selective monoamine oxidase inhibitors on the in vivo release and metabolism of dopamine in the rat striatum. J Neurochem 55:981-988.

Commissioning JW (1985) Monoamine metabolites: their relationship to monoaminergic neuronal activity. Biochem Pharmacol 34:1127-1131.

Church WH, Justice IBJ, Byrd LD (1987) Extracellular dopamine in rat striatum following uptake inhibition by cocaine, nomifensine and benztropine. Eur J Pharmacol 139:345-348.

Di Chiara G, Imperato A (1988) Drugs abused by humans preferentially increase synaptic dopamine concentrations in the mesolimbic system of freely moving rats. Proc Natl Acad Sci USA 85:5274-5278.

Einhorn LC, Johansen PA, White FJ (1988) Electrophysiological effects of cocaine in the mesoaccumbens dopamine system: studies in the ventral tegmental area. J Neurosci 8:100-112.

Flower CJ, Strolin Benedetti M (1982) The metabolism of dopamine by both forms of monoamine oxidase in the rat brain and its inhibition by cimoxatone. J Neurochem 40:1534-1541.

Galloway MP (1988) Neurochemical interactions of cocaine with dopaminergic systems. Trends Pharmacol Sci 9:451-454.

Grace AA, Onn SP (1989) Morphology and electrophysiological properties of immunocytochemically identified rat dopamine neurons recorded in vitro. J Neurosci 9:3463-3481.

Green AR, Mitchell BD, Tordoff AFC, Youdim MBH (1977) Evidence for dopamine deamination by both type A and type B monoamine oxidase in rat brain in vivo and for the degree of inhibition of enzyme necessary for increased functional activity of dopamine and 5-hydroxytryptamine. Br J Pharmacol 60:343-349.

Harsing LA, Vizi ES (1984) Release of endogenous dopamine from rat isolated striatum: effect of clorgyline and (-)deprenyl. Br J Pharmacol 83:741-749.

Houslay MD, Tipton KF, Youdim MBK (1976) Multiple forms of monoamine oxidase: fact and artifact. Life Sci 19:467-478.

Johnston JP (1968) Some observations upon a new inhibitor of monoamine oxidase in brain tissue. Biochem Pharmacol 17:1285-1295.

Johnson SW, North RA (1992) Two types of neurons in the rat ventral tegmental area and their synaptic inputs. J Physiol (Lond) 450:455-468.

Juorio AV, Paterson IA, Zhu MY (1994) Dopamine metabolism in the guinea pig striatum: role of monoamine oxidase A and B. Eur J Pharmacol 254:213-220.

Kalivas PW, Duffy P (1991) A comparison of axonal and somatodendritic dopamine release using in vivo dialysis. J Neurochem 56:961-966.

Kita T, Kita H, Kitai ST (1986) Electrical membrane properties of rat substantia nigra compacta neurons in an in vitro slice preparation. Brain Res 372:21-30.

Kito S, Shimoyama M, Arakawa R (1986) Effects of neurotransmitters or drugs on the in vivo release of dopamine and its metabolites. Jpn J Pharmacol 40:57-67.

Knoll J, Magyar K (1972) Some puzzling effects of monoamine oxidase inhibitors. In: Monoamine oxidase-new vista (Costa E, Sandler M, eds), pp 393-408. New York: Raven.

Lacey MG, Mercuri NB, North RA (1987) Dopamine acts on D2 receptors to increase potassium conductances in neurones of the rat substantia nigra zona compacta. J Physiol (Lond) 392:397-416.

Lacey MG, Mercuri NB, North RA (1989) Two cell types in rat substantia nigra zona compacta distinguished by membrane properties and the action of dopamine and opioids. J Neurosci 9:1233-1241.

Lacey MG, Mercuri NB, North RA (1990) Actions of cocaine on rat dopaminergic neurones in vitro. Br J Pharmacol 98:731-735.

Levitt P, Pintar JE, Breakefield XO (1982) Immunocytochemical demonstration of monoamine oxidase B in brain astrocytes and serotoninergic neurons. Proc Natl Acad Sci USA 79:6385-6389.

Llinas RR, Greenfield SA, Jahnsen H (1984) Electrophysiology of pars compacta cells in the in vitro substantia nigra: a possible mechanism for dendritic release. Brain Res 294:127-132.

Marsden CA, Broch Jr OJ, Gulldberg HC (1972) Effect of nigral and raphe lesions on the catechol-o-methyl transferase and monoamine oxidase activities in the rat striatum. Eur J Pharmacol 19:35-42.

Mercuri NB, Calabresi P, Bernardi G (1989) The mechanism of amphetamine-induced inhibition of rat substantia nigra compacta neurones investigated with intracellular recording in vitro. $\mathrm{Br} \mathrm{J}$ Pharmacol 98:127-134.

Mercuri NB, Calabresi P, Bernardi G (1990) Responses of rat substantia nigra compacta neurones to L-DOPA. Br J Pharmacol 100:257-260.

Mercuri NB, Calabresi P, Bernardi G (1991a) Dopamine uptake inhibition potentiates the effects of L-DOPA on rat substantia nigra neurons. Neurosci Lett 126:79-82.

Mercuri NB, Stratta F, Calabresi P, Bernardi G (1991b) Nomifensine but not amantadine increases dopamine-induced responses on rat substantia nigra zona compacta neurons. Neurosci Lett 131:145-148.

Mercuri NB, Stratta F, Calabresi P, Bernardi G (1991c) Electrophysiological effect of amineptine on neurons of the rat substantia nigra pars compacta: evidence for an inhibition of the dopamine-uptake system. Br J Pharmacol 104:700-704.

Mercuri NB, Bonci A, Calabresi P, Stratta F, Bernardi G (1995) Properties of the hyperpolarization-activated cation current $I_{\mathrm{h}}$ in rat midbrain dopaminergic neurons. Eur J Neurosci 7:462-469.

Mercuri NB, Bonci A, Siniscalchi A, Stefani A, Calabresi P, Bernardi G (1996) Electrophysiological effects of monoamine oxidase inhibition on rat midbrain dopaminergic neurons: an in vitro study. Br J Pharmacol 117:528-532.

Nomikos GG, Damsma G, Wenkstern D, Fibiger HC (1990) In vivo characterization of dopamine uptake inhibitors by reverse brain microdialysis. Synapse 6:106-112.

Roffler-Tarlov S, Sharman DF, Tergendine P (1971) 3,4- Dihydroxyphenylacetic acid in the mouse striatum: a reflection of intra- and extraneuronal metabolism of dopamine? Br J Pharmacol 42:343-351.

Saura J, Kettler R, Da Prada M, Richards JC (1992) Quantitative enzyme radioautography with $\left[{ }^{3} \mathrm{H}\right] \mathrm{Ro} 41-1049$ and $\left[{ }^{3} \mathrm{H}\right] \mathrm{Ro} 19-6327$ in vitro: localization and abundance of MAO A and B in rat CNS, peripheral organs, and human brain. J Neurosci 12:1977-1999.

Saura J, Bleuel Z, Ulrich J, Mendelowitsch A, Chen K, Shih JC, Malherbe P, Da Prada M, Richards JC (1996) Molecular neuroanatomy of human monoamine oxidase $\mathrm{A}$ and $\mathrm{B}$ revealed by quantitative enzyme radioautography and in situ hybridization histochemistry. Neuroscience 70:755-774.

Schoepp DD, Azzaro AJ (1982) The role of type A and type B monoamine oxidase in the metabolism of released $\left[{ }^{3} \mathrm{H}\right]$ dopamine from rat striatal slices. Biochem Pharmacol 31:2961-2968.

Schoepp DD, Azzaro AJ (1983) Effects of intrastriatal kainic acid injection on $\left[{ }^{3} \mathrm{H}\right]$ dopamine metabolism in rat striatal slices: evidence for postsynaptic glial cell metabolism by both the type A and B forms of monoamine oxidase. J Neurochem 40:1340-1348.

Weiner N, Molinoff PB (1989) Storage and release of catecholamines. In: Basic neurochemistry: molecular, cellular, and medical aspects (Siegel G, Agranoff B, Albers RW, Molinoff P, eds), pp 236-239. New York: Raven.

Williams JT, Lacey MG (1989) Actions of cocaine on central monoamine neurons: intracellular recordings in vitro. Natl Inst Drug Abuse Res Monogr Ser 90:234-242.

Yang HY, Neff NH, (1974) The monoamine oxidase of brain: selective inhibition with drugs and the consequence for the metabolism of biogenic amine. J Pharmacol Exp Ther 189:733-740. 